\section{Chair of Natural Philosophy at St. Andrews: Prof. H. Stanley Allen, F.R.S.}

Prof. H. Stanley Alten has retired from the chair of natural philosophy in the University of St. Andrews. His life in St. Andrews has been one of quiet painstaking work characterized by thoroughness in everything he undertook. His highest quality was a constant striving for the clearest, the best, way in which he could present a point. A simple example is his treatment of entropy. He has stated that in his opinion it is necessary that the beginner in a scientific subject should be given at the outset some familiar mental picture. He then points out that momentum is a vector quantity depending on the first power of the velocity, and remarks that therefore it is not likely to be a suitable analogy for entropy. It has to be remembered that Kelvin's definition of entropy makes it vary directly with the heat and inversely with the temperature. $\mathrm{He}$ then points out that on the basis of the kinetic theory of gases, not only the square of the velocity is involved, but also the time taken by one molecule to pass over the space in the near neighbourhood of any other. He finally shows that Callendar's identification of the energy with the form $\frac{1}{2} Q V^{2}$ gives agreement. Prof. Allen has spent twenty years of his life in St. Andrews, and the sympathy of everyone who knows him will go out to him in his.recent great loss through the death of his wife. All will entertain the hope that the greater freedom from routine labour consequent on his retirement may enable him to devote more time directly to the service of the science in which he takes his delight.

Prof. J. T. Randall

Dr. J. T. Randall has been appointed to the chair of natural philosophy in the United College, St. Andrews, in succession to Prof. H. Stanley Allen. Dr. Randall was educated at the Victoria University of Manchester under Prof. W. L. Bragg, and before joining the staff of the Research Laboratories of the General Electric Company, Ltd., Wembley, carried out research work on the scattering powers of atoms for X-rays. In 1937 he was elected a Royal Society Warren research fellow, and joined Prof. M. L. E. Oliphant in the University of Birmingham, where an intensive study of the mechanism of luminescence in solids was carried out. Publication of much of this work has been delayed for security reasons. At the outbreak of war Dr. Randall turned his attention to problems associated with radiolocation, and succeeded with Dr. H. A. H. Boot in introducing a new type of apparatus which has resulted in the saving of many lives at sea. For this work Dr. Randall and Dr. Boot were recently awarded the Thomas Gray Memorial Prize of the Royal Society of Arts. Since 1943 Dr. Randall has been a temporary lecturer in the Cavendish Laboratory, Cambridge.

\section{Prof. William Wilson, F.R.S.}

Prof. Wrulram Wruson, who has recently retired from the Hildred Carlile chair of physics at Bedford College, University of London, spent his student days at the Universities of London and Leipzig, and he found much to admire in the freedom of the German university system of those days and in the men who sustained it. In his early years as a physicist, he carried out much pioneer experimental work on photo-electric emission and developed a quantum theory of thermionic emission, which was published in 1912. By 1915 he had discovered the quantum relation $\int p . d q=n . h$, and by introducing two quantum numbers, he found an expression for the eccentricities of the elliptic orbits of electrons; thus he opened up a large field of progress in the study of atomic structure. In 1921 he introduced the concept of generalized momentum into the theory of the electromagnetic field, and has since become much interested in Kaluza's five-dimensional theory of relativity. He was elected a fellow of the Royal Society in 1923.

It is only possible to mention a few of Prof. Wilson's many contributions to physics; he is more familiar than many scientific men with the work of physicists and mathematicians of the past, and his own work has in consequence a rare maturity and understanding. $\mathrm{He}$ thinks in an original way about all the fundamental principles of physics. Besides his writings in scientific journals, he completed in 1940 the third volume of a work on "Theoretical Physics", which is the culmination of his lectures to advanced students. It is a unifying account of many aspects of the subject and has great elegance of style. Prof. Wilson has always delighted to share his knowledge and wisdom with others and this makes him a great teacher. Besides his o.ticial pupils, many of his colleagues and fellow workers have sought and obtained help and instruction from him. He has served the University of London in many capacities, including that of senator, member of the External Council and chairman of the Board of Studies in Physics.

\section{Structure of the Kiogar Mountains}

Dr. E. B. BAILEY, director of the Geological Survey of Great Britain, gave a Friday discourse on November 3 at the Royal Institution on "Mountains that have Travelled Over Volcanoes". Many mountain chains present a complexity of internal structure which recalls, with great magnification, that of pack ice piled sheet upon sheet by a tempest of yesterday. In 1893 it was realized by geologists studying the Alps that a far-travelled thrust-sheet may often be distinguished by the foreign characteristics of its constituent geolozical formations, just as clearly as a far-travelled man by the foreign characteristics of his face and dress. The Kiogar mountains on the borders of Tibet and India illustrate this phenomenon to perfection. The rock formations making the summits have very special characters spoken of collectively as Tibetan. The underlying formations making the lower slopes are shown by their fossils to be of the same geological age as the Tibetan formations overhead; but they have much more familiar characters spoken of collectively as Himalayan. Between the Tibetan and the Himalayan developments lies a thick separating complex layer of igneous rocks. Some of these igneous rocks are submarine lavas, following in normal succession upon the underlying Himalayan sediments. Some, however, exhibit intrusive relations and penetrate the overlying Tibetan sediments. The conclusion is reached that in the days before the upheaval of the local sea bottom to give the Himalayan mountains, an invading thrust-sheet penetrated the area from the north. On its way it passed over a group of submarine volcanoes, which, driven underground, maintained a guerilla attack by injection of molten material from below. Wear and tear due to withdrawal of over-run, overloaded mobile sediments added to the general confusion. 